Литвинчук Леся Михайлівна доктор психологічних наук, старший науковий співробітник, Національний авіаційний університет, Україна, проспект Любомира Гузара, 1, м. Київ, 03058, тел.: (044) 406-79-01, e-mail: lutol@ukr.net, https://orcid.org/0000-0002-5085-4499

\title{
ПРОБЛЕМА ДОСЛІДЖЕННЯ РІВНЯ КОМУНІКАБЕЛЬНОСТІ У СИСТЕМІ «ЛІКАР-ПАЦІЕНТ»
}

Анотація. У статті висвітлено результати емпіричного дослідження рівня комунікабельності у системі «лікар-пацієнт». Зясовано, що медперсонал середньої ланки протягом тривалого часу знаходиться в безпосередньому контакті 3 пацієнтом, тому може здійснювати як позитивний, так і негативний вплив на пацієнта. Завдання медперсоналу максимально уникати непотрібних негативних психологічних впливів, сприяти створенню психологічного клімату, сприятливо впливає на процес одужання.

Обмін інформацією грунтується на відносинах між активними суб'єктами процесу. Передача та прийом інформації здійснюється у процесі безперервного аналізу стану, цілей, мотивів лікаря та пацієнта як учасників спілкування та корекції ними власних дій. Наслідком активності учасників даної комунікації $є$ зміна інформації в процесі передачі-прийому. По-друге, обмін інформації припускає вплив на поведінку комініканта за допомогою системи знаків, що призводять до зміни станів та позицій. По-третє, розуміння інформації, що передається, а також результативність впливу на поведінку пацієнта прямо пов'язані з наявністю єдиної системи знань, якою користуються комунікатор та реципієнт при кодуванні та декодуванні повідомлень. Іншими словами, учасники комунікативного процесу повинні мати загальний «тезаурус», тобто сукупність значень, що використовують символічні засоби комунікації. По-четверте, в процесі передачі інформації та iii розуміння можлива поява комунікативних бар'єрів, що мають соціальний чи психологічний характер.

Проблема комунікації «лікар-пацієнт» передбачає міждисциплінарний підхід із залученням лікарів, медичних психологів, соціо- та психолінгвістів.

Проведений аналіз наукової летератури показує, що певні аспекти мовного спілкування лікаря надзвичайно важливо враховувати і невербальні аспекти комунікації з пацієнтом. Комунікація в контексті кардіологічного лікування, іiі успішність, результативність розглядається як динамічний процес із характерними вербальними i невербальними стратегіями i тактиками поведінки, серед якої неостаннє місце припадає доброзичливості.

Сучасний пацієнт не задовольняється традиційно пасивною роллю, а проявляе прагнення до активної комунікації, бажаючи бути почутим i 
зрозумілим лікарем. У зв'язку з цим лікаря принципово важливо володіти навичками правильної побудови бесіди 3 пацієнтом, націленої на дозвіл лікувальної ситуації, не обмежуючи при цьому надій і очікувань пацієнта.

Ключові слова: комунікабельність, доброзичливість. лікар, пацієнт, ефективність лікувального процесу.

Lytvynchuk Lesia Mykhaylivna Ph.D. in Psychology, Senior Researcher Aviation psychology Department, National aviation University, 1, Liubomyra Huzara avenue, Kyiv 03058, tel.: (044) 406-79-01, e-mail: lutol@ukr.net, https://orcid.org/ 0000-0002-5085-4499

\section{THE PROBLEM OF STUDYING THE LEVEL OF COMMUNICABILITY IN THE "DOCTOR-PATIENT" SYSTEM}

Abstract. Mid-level medical staff is in direct contact with the patient for a long time, so it can have both positive and negative effects on the patient. The task of the medical staff is to avoid unnecessary negative psychological influences as much as possible, to promote the creation of a psychological climate, which has a positive effect on the healing process.

The exchange of information is based on the relationship between the active subjects of the process. The transmission and reception of information is carried out in the process of continuous analysis of the condition, goals, motives of the doctor and the patient as participants in communication and correction of their own actions. The consequence of the activity of the participants of this communication is the change of information in the process of transmission and reception. Second, the exchange of information involves influencing the behavior of the communicant through a system of signs that lead to changes in states and positions. Third, the understanding of the information transmitted, as well as the effectiveness of influencing patient behavior, are directly related to the existence of a single system of knowledge used by the communicator and the recipient in encoding and decoding messages. In other words, participants in the communicative process must have a common "thesaurus", ie a set of meanings that use symbolic means of communication. Fourth, in the process of transmitting and understanding information, communication barriers of a social or psychological nature may emerge.

The problem of "doctor-patient" communication involves an interdisciplinary approach involving doctors, medical psychologists, socio- and psycholinguists.

The analysis of the scientific literature shows that certain aspects of the doctor's language communication are extremely important to take into account the non-verbal aspects of communication with the patient. Communication in the context of cardiac treatment, its success, effectiveness is seen as a dynamic process with characteristic verbal and nonverbal strategies and tactics of behavior, among which the last place is benevolence, wanting to be heard and understood by the doctor. In this regard, it is essential for a doctor to have the skills to properly construct a conversation with the patient, aimed at resolving the treatment 
situation, without limiting the patient's expectations and expectations. that is, the ability not to perceive adverse effects in patients that may occur at certain stages of treatment; have the appropriate level of trust, remove barriers to communication and at the same time be friendly.

Keywords: sociability, friendliness. doctor, patient, the effectiveness of the treatment process.

Постановка проблеми. Сучасні медичні технології породили суперечності поміж лікарем та пацієнтом. Цю систему взаємин схематично відтворюють як «лікар - прилад - хворий». У цих умовах медик працює 3 іншими розумовими, моральними та психологічними категоріями, а увага розподіляється між хворим та інформацією, що надходить із діагностичних кабінетів чи лабораторій. Оскільки в обстеженні та лікуванні пацієнта задіяно чимало спеціалістів, увагу часто сконцентровано на окремій системі органів або певному органі, що унеможливлює сприйняття проблеми пацієнта у комплексі. Науково-технічний прогрес у медицині значно покращив можливості розпізнавання хвороб, втім у лікаря виробляється звичка користуватись отриманими технічно-діагностичними даними, не враховуючи індивідуальні особливості пацієнта або його психологічний стан. Особливо важливу роль це відіграє тоді, коли перебіг хвороби безпосередньо пов'язаний із емоційним станом.

На сьогоднішній день існує досить багато підходів до проведення психологічного експерименту. Виходячи із завдань нашого дослідження, а саме дослідження рівня комунікабельності у системі «лікар-пацієнт», доцільним буде структуризувати експеримент із позиції системного підходу, за якого експеримент є системою, а отже, має мету, суб'єкт, об'єкт, визначені взаємовпливи між ними, певну ієрархічну структуру та результат.

Аналіз останніх досліджень і публікацій. В останні роки проведено значну кількість досліджень, що розкривають психологічні аспекти медичної діяльності, зокрема і комунікації (А. Василькова, О.Грандо, С. Грандо, Ф. Портнов, В. Ташликов, Т. Трибрат, В. Чугунов, В. Шепітько, С. Шуть та ін.). Проте зазначені роботи не вичерпують вивчення комунікативної компетентності лікаря.

Мета статті - дослідження дослідження рівня комунікабельності у системі «лікар-пацієнт»в Україні.

\section{Виклад основного матеріалу.}

Комунікабельність (від лат. cjmmunicabilis — з'єдную, здатність людини до спілкування, до встановлення соціальних зв'язків, контактів, до плідної взаємодії з іншими людьми. У психології спілкування вміння налагоджувати контакти, здатність до конструктивного спілкуванню 3 іншими людьми. Комунікабельність є однією 3 визначальних навичок успішної соціальної взаємодії, що зачіпає як професійні, так і особистісні стосунки. Комунікабельність $є$ однією 3 найважливіших особистісних якостей в професіях, які передбачають активне спілкування 3 іншими людьми, такими як, наприклад, менеджер 3 продажу, менеджер зі зв'язків 3 
громадськістю, менеджер 3 персоналу. Одна 3 рис успішної взаємодії - це неупередженість у відношенні до чужих поглядів. Згідно Тесвальду і Пуну (Tjosvold i Poon), неупередженість це психологічна концепція, згідно з якою люди розглядають погляди і знання інших людей, «при цьому розуміючи, що інші повинні бути вільні у вираженні їхніх поглядів, і що значення знань інших людей має бути визнано»[1].

Відповідно до класифікації професій, запропонованої Е. Клімовим, медичні працівники є представниками соціономічного типу професій, у яких центральне місце посідають взаємні контакти 3 людьми [2]. Медична діяльність має специфічний характер, оскільки в центрі уваги постає особа, що має психічні та фізичні страждання, викликані хворобою. Відповідно, необхідно враховувати особливу чутливість, вразливість і порушену психічну стійкість пацієнта.

3'ясовано, що медична діяльність будується не тільки на знаннях анатомо-фізіологічних особливостей людського організму, а й передбачає певний психологічний вплив на людину, що грунтується не стільки на заборонах i приписах, скільки на знанні закономірностей людського спілкування.

У той же час вивчення проблеми спілкування пов'язане 3 низкою методологічних труднощів, зокрема, різною інтерпретацією понять, які використовуються 3 метою опису процесів спілкування, а також відмінностями в поясненні природи та сутності цього процесу. Розбіжності, як правило, стосуються можливості розуміння спілкування як діяльності. У вітчизняній науці $є$ дві точки зору на поняття «спілкування»: спілкування як вид діяльності (Б. Ананьєев, А. Леонтьєв) і спілкування як самостійний процес (Б. Ломов, А. Реан) [3].

Процес спілкування, який підтримується потребами у спільній діяльності людей, здійснюється за схемою «суб'єкт-об'єкт». У сфері медицини є низка галузей, де саме дії визначають професіоналізм, наприклад, невідкладна допомога, хірургія та ін. Лікарі в даних випадках здійснюють діяльність, яку можна описати, оцінити, виміряти. Спеціальні контрольні служби можуть перевірити, чи відповідають дії медичного працівника стандартам і нормам професійної етики.

Мюнхенським невропатологом О. Бумке в 1925 році було зазначено, «... що невміла бесіда лікаря може привести до того, що до соматичного захворювання приз'єднається психоневроз». У деонтологічній літературі неодноразово наголошується, що ефективними ліками є сам лікар [4].

Спілкування між лікарем i пацієнтом можна розглядати як функціонально-рольове міжособистісне спілкування, яке протікає згідно 3 культурно обумовленими нормами і правилами виконання вимог цієї ролі. Формально рольове спілкування дозволяє лікарю залишатися в межах зовнішнього, поведінкового впливу, орієнтованого на вимоги, соціальні норми і статус та не вимагає глибокого взаєморозуміння.

Як показала практика, медичні працівники, коли розуміли, що за їх комунікативними діями спостерігають експерти, поводили себе в багатьох 410 
випадках неприродньо. Дехто з лікарів мобілізувався і показував дуже високі результати, а дехто - навпаки (особливо молоді медики із невеликим стажем роботи), комунікували із пацієнтами більш сковано, затиснуто, невпевнено ніж зазвичай. Тому, зокрема, спроба використання модифікованої методики J. Cox та H. Mulholland вийшла невдалою. Самі автори методики вийшли із положення, встановлюючи відеокамери для спостереження за комунікацією між медиками та пацієнтами. Відомим є феномен, коли люди звикають до наявності камер і перестають на них зважати. Проте застосування засобів відеозапису нами було визнано неможливим, як з етичних, так і з фінансових міркувань.

На констатувальному етапі експерименту в дослідженні взяли участь 73 медичні працівники кардіологічного профілю (лікарі та інтерни) різних медичних закладів. Із них було сформовано контрольну групу (далі КГ) у складі 26 осіб та експериментальну (відповідно, 47 осіб, ЕГ).

За основу було взято опитувальник В. Ряховського для визначення рівня комунікабельності. Тест В. Ряховського для визначення рівня комунікабельності містить 16 запитань, на кожне 3 яких слід відповісти однозначно: “так”, “ні” чи “інколи”. Результати тесту дають можливість за класифікатором визначити, до якої з категорій відноситься піддослідний.

Зведені результати обох тестувань за цією методикою були занесені до Таблиці 1.

Таблиия 1

\section{Результати діагностики рівня комунікабельності за В. Ряховським}

\begin{tabular}{|c|c|c|c|c|c|c|c|c|c|c|c|}
\hline \multirow[b]{2}{*}{ 㿣 } & \multirow[b]{2}{*}{ 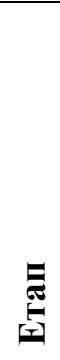 } & \multirow[b]{2}{*}{$\mathbf{E}_{\text {cep }}$} & \multirow[b]{2}{*}{$\mathbf{E}_{\max }$} & \multirow[b]{2}{*}{$\mathbf{K}_{3}$} & \multicolumn{7}{|c|}{ Рівень } \\
\hline & & & & & 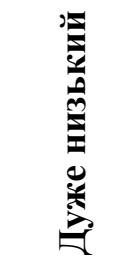 & 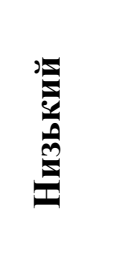 & 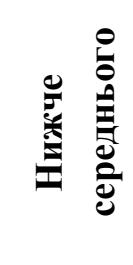 & نे & 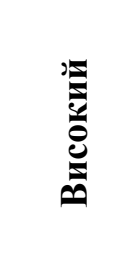 & 兽兽 & 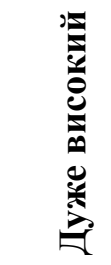 \\
\hline \multirow{2}{*}{ КГ } & $\mathrm{K}$ & 15,65 & \multirow{4}{*}{32} & $51,09 \%$ & $7,69 \%$ & $\begin{array}{c}11,54 \\
\%\end{array}$ & $\begin{array}{l}15,38 \\
\%\end{array}$ & $\begin{array}{l}19,23 \\
\%\end{array}$ & $\begin{array}{l}23,08 \\
\%\end{array}$ & $\begin{array}{l}15,38 \\
\%\end{array}$ & $7,69 \%$ \\
\hline & $\Phi$ & 15,31 & & $52,16 \%$ & $3,85 \%$ & $\begin{array}{l}15,38 \\
\%\end{array}$ & $\begin{array}{l}15,38 \\
\%\end{array}$ & $\begin{array}{l}19,23 \\
\%\end{array}$ & $\begin{array}{c}23,08 \\
\%\end{array}$ & $\begin{array}{l}11,54 \\
\%\end{array}$ & $\begin{array}{l}11,54 \\
\%\end{array}$ \\
\hline \multirow{2}{*}{$\mathrm{E} \Gamma$} & K & 16,21 & & $49,3 \%$ & $8,51 \%$ & $\begin{array}{l}12,77 \\
\%\end{array}$ & $\begin{array}{l}14,89 \\
\%\end{array}$ & $\begin{array}{l}19,15 \\
\%\end{array}$ & $\begin{array}{l}21,28 \\
\%\end{array}$ & $\begin{array}{l}14,89 \\
\%\end{array}$ & $8,51 \%$ \\
\hline & $\Phi$ & 14,53 & & $54,59 \%$ & $6,38 \%$ & $8,51 \%$ & $\begin{array}{l}12,77 \\
\%\end{array}$ & $\begin{array}{l}21,28 \\
\%\end{array}$ & $\begin{array}{l}23,40 \\
\%\end{array}$ & $\begin{array}{l}14,89 \\
\%\end{array}$ & $\begin{array}{l}12,77 \\
\%\end{array}$ \\
\hline
\end{tabular}

Розглянемо Т-критерій Вілкоксона для експериментальної групи, прийнявши за нетиповий зсув «нульове значення» та враховуючи нульові зсуви. 
Табличя 2

Розрахунок суми рангів нетипових зсувів для експериментальної групи, за опитувальником В. Ряховського для визначення рівня комунікабельності

\begin{tabular}{|c|c|c|c|c|c|c|c|c|c|c|c|}
\hline $\mathbf{N}$ & До & Після & $\begin{array}{l}3 \text { cyB } \\
d_{i}\end{array}$ & $\begin{array}{l}\text { Абс. } \\
\text { знач. } \\
\text { зсуву }\end{array}$ & $\begin{array}{l}\text { Рангов } \\
\text { ий } \\
\text { номер } \\
\text { зсуву }\end{array}$ & $\mathbf{N}$ & До & Після & $\begin{array}{l}\text { 3cyB } \\
d_{i}\end{array}$ & $\begin{array}{l}\text { Абс. } \\
\text { знач. } \\
\text { зсуву }\end{array}$ & $\begin{array}{l}\text { Рангов } \\
\text { ий } \\
\text { номер } \\
\text { зсуву }\end{array}$ \\
\hline 1 & 1 & 1 & 0 & 0 & 3 & 25 & 15 & 14 & -1 & 1 & 14.5 \\
\hline 2 & 1 & 1 & 0 & 0 & 3 & 26 & 16 & 15 & -1 & 1 & 14.5 \\
\hline 3 & 2 & 1 & -1 & 1 & 14.5 & 27 & 17 & 5 & -2 & 2 & 32.5 \\
\hline 4 & 3 & 2 & -1 & 1 & 14.5 & 28 & 18 & 16 & -2 & 2 & 32.5 \\
\hline 5 & 4 & 3 & -1 & 1 & 14.5 & 29 & 18 & 16 & -2 & 2 & 32.5 \\
\hline 6 & 5 & 3 & -2 & 2 & 32.5 & 30 & 18 & 16 & -2 & 2 & 32.5 \\
\hline 7 & 6 & 5 & -1 & 1 & 14.5 & 31 & 19 & 17 & -2 & 2 & 32.5 \\
\hline 8 & 7 & 6 & -1 & 1 & 14.5 & 32 & 22 & 17 & -5 & 5 & 45.5 \\
\hline 9 & 7 & 6 & -1 & 1 & 14.5 & 33 & 22 & 17 & -5 & 5 & 45.5 \\
\hline 10 & 8 & 7 & -1 & 1 & 14.5 & 34 & 23 & 17 & -6 & 6 & 47 \\
\hline 11 & 8 & 7 & -1 & 1 & 14.5 & 35 & 23 & 21 & -2 & 2 & 32.5 \\
\hline 12 & 9 & 8 & -1 & 1 & 14.5 & 36 & 24 & 22 & -2 & 2 & 32.5 \\
\hline 13 & 10 & 8 & -2 & 2 & 32.5 & 37 & 24 & 23 & -1 & 1 & 14.5 \\
\hline 14 & 11 & 9 & -2 & 2 & 32.5 & 38 & 26 & 23 & -3 & 3 & 43 \\
\hline 15 & 11 & 10 & -1 & 1 & 14.5 & 39 & 26 & 24 & -2 & 2 & 32.5 \\
\hline 16 & 12 & 10 & -2 & 2 & 32.5 & 40 & 27 & 24 & -3 & 3 & 43 \\
\hline 17 & 12 & 10 & -2 & 2 & 32.5 & 41 & 27 & 25 & -2 & 2 & 32.5 \\
\hline 18 & 12 & 11 & -1 & 1 & 14.5 & 42 & 29 & 27 & -2 & 2 & 32.5 \\
\hline 19 & 13 & 12 & -1 & 1 & 14.5 & 43 & 29 & 29 & 0 & 0 & 3 \\
\hline 20 & 13 & 12 & -1 & 1 & 14.5 & 44 & 32 & 29 & -3 & 3 & 43 \\
\hline 21 & 13 & 13 & 0 & 0 & 3 & 45 & 32 & 30 & -2 & 2 & 32.5 \\
\hline 22 & 14 & 13 & -1 & 1 & 14.5 & 46 & 32 & 30 & -2 & 2 & 32.5 \\
\hline 23 & 14 & 13 & -1 & 1 & 14.5 & 47 & 32 & 32 & 0 & 0 & 3 \\
\hline 24 & 15 & 13 & -2 & 2 & 32.5 & & & & & & \\
\hline \multicolumn{11}{|c|}{ Сума рангів нетипових зсувів } & 15 \\
\hline
\end{tabular}

Результат порівняння: $\mathrm{T}_{\text {емп }}=\mathbf{1 5}$;

Критичні значення при $\mathrm{n}=47: \mathrm{p} \leq 0,01: \mathrm{T}_{\text {кр }}=345 ; \mathrm{p} \leq 0,05: \mathrm{T}_{\text {кр }}=407$;

Таким чином, було визначено, що Т-критерій Вілкоксона попадає у зону значущості, а отже, у результаті проведення впливу на рівень комунікабельності, за В. Ряховським, на етапі фомального експерименту 
методики відбулися позитивні зрушення.

Для визначення ступеню цих зрушень (тісноти, сили) скористуємось коефіцієнтом кореляції Спірмена ( $\rho$ ) та його інтерпритацією за допомогою шкали Чеддока. Коефіцієнт кореляції Спірмена:

$$
\rho=1-\frac{6 \sum d_{i}^{2}}{n\left(n^{2}-1\right)}=0.998
$$

Де $\mathrm{d}_{\mathrm{i}}-$ значення із Таблиці 2.21., $\mathrm{n}=47$.

Критичне значення критерію Спірмена при $\mathrm{n}=47$ i $\mathrm{p}<0,01$ становить 0.37 .

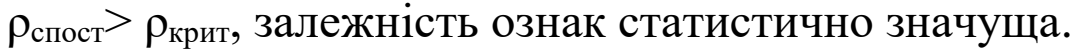

Зв'язок між досліджуваними ознаками - прямий, тіснота (сила) зв'язку за шкалою Чеддока - дуже висока.

Для контрольної групи за нетиповий зсув було прийнято «зменшення значення», за умови неврахування нульових зсувів.

Таблиия 3

Розрахунок суми рангів нетипових зсувів для контрольної групи за опитувальником В. Ряховського для визначення рівня комунікабельності

\begin{tabular}{|c|c|c|c|c|c|c|c|c|c|c|c|}
\hline $\mathbf{N}$ & До & Після & 3сув $d_{i}$ & $\begin{array}{l}\text { Абс. } \\
\text { знач. } \\
\text { зсуву }\end{array}$ & $\begin{array}{l}\text { Рангови } \\
\text { й номер } \\
\text { зсуву }\end{array}$ & $\mathbf{N}$ & До & Після & $\begin{array}{l}3 c y B \\
d_{i}\end{array}$ & $\mid \begin{array}{l}\text { бс. } 3 н а \\
\text { уву }\end{array}$ & $\begin{array}{l}\text { Рангови } \\
\text { й номер } \\
\text { зсуву }\end{array}$ \\
\hline 1 & 1 & 1 & 0 & 0 & 9 & 14 & 18 & 17 & -1 & 1 & 22 \\
\hline 2 & 2 & 2 & 0 & 0 & 9 & 15 & 18 & 18 & 0 & 0 & 9 \\
\hline 3 & 4 & 3 & -1 & 1 & 22 & 16 & 18 & 18 & 0 & 0 & 9 \\
\hline 4 & 5 & 5 & 0 & 0 & 9 & 17 & 18 & 18 & 0 & 0 & 9 \\
\hline 5 & 6 & 6 & 0 & 0 & 9 & 18 & 21 & 21 & 0 & 0 & 9 \\
\hline 6 & 6 & 5 & -1 & 1 & 22 & 19 & 23 & 22 & -1 & 1 & 22 \\
\hline 7 & 9 & 9 & 0 & 0 & 9 & 20 & 23 & 23 & 0 & 0 & 9 \\
\hline 8 & 9 & 9 & 0 & 0 & 9 & 21 & 24 & 23 & -1 & 1 & 22 \\
\hline 9 & 10 & 10 & 0 & 0 & 9 & 22 & 25 & 25 & 0 & 0 & 9 \\
\hline 10 & 11 & 11 & 0 & 0 & 9 & 23 & 26 & 25 & -1 & 1 & 22 \\
\hline 11 & 12 & 12 & 0 & 0 & 9 & 24 & 28 & 28 & 0 & 0 & 9 \\
\hline 12 & 13 & 12 & -1 & 1 & 22 & 25 & 30 & 29 & -1 & 1 & 22 \\
\hline 13 & 15 & 15 & 0 & 0 & 9 & 26 & 32 & 31 & -1 & 1 & 22 \\
\hline \multicolumn{11}{|c|}{ Сума рангів нетипових зсувів } & 198 \\
\hline
\end{tabular}

Результат порівняння: $\mathrm{T}_{\text {емп }}=\mathbf{1 9 8}$;

Критичні значення при $\mathrm{n}=26: \mathrm{p} \leq 0,01: \mathrm{T}_{\text {кр }}=84 ; \mathrm{p} \leq 0,05: \mathrm{T}_{\text {кр }}=110$; 


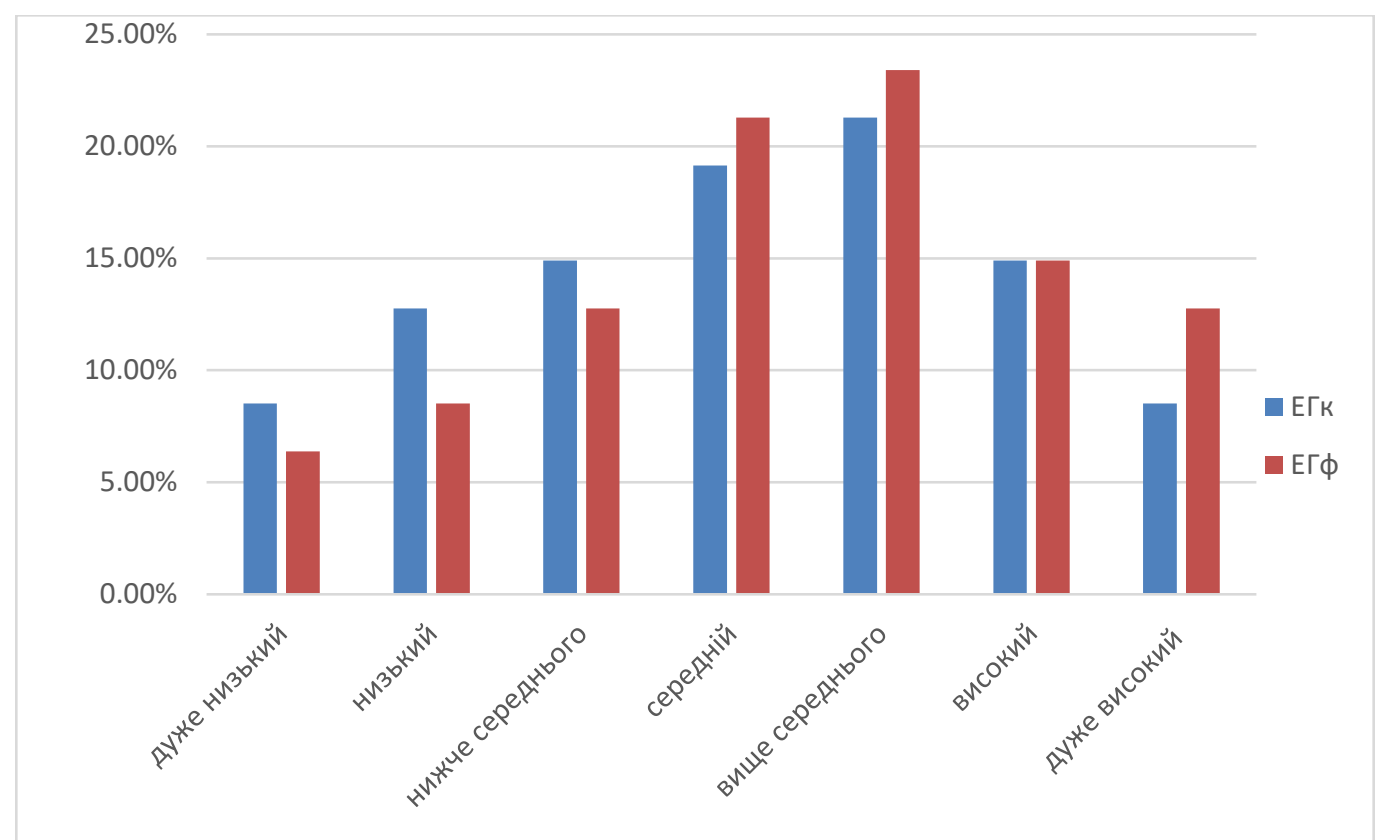

Pис.1. Зміни в комунікабельності за рівнями (методика В. Ряховського)

Таким чином, можна відзначити, що для контрольної групи Y після вимірювання на другому етапі спостерігається приріст значень, для якого $\mathrm{T}_{\text {емп }}=198$ знаходиться $\mathrm{y}$ зоні незначущості. Отже, ми отримали підтвердження, що завдяки здійсненому нами цілеспрямованому впливу відбулися позитивні зміни в рівні комунікабельності для експериментальної групи, за опитувальником В. Ряховського (рис. 1), на відміну від контрольної, у якій теж прослідковується наявність позитивних змін, проте вони не набувають рівня статистичної значущості.

Висновки. Лікувально-діагностичний процес розглядається як спільна діяльність лікаря і хворого. Ефективність комунікації, яка тісно вплетена в контекст професійної діяльності медика, не може не позначатися на результатах цієї діяльності. Узагальнення результатів проведеного дослідження надає можливість зробити висновок про рівень розвитку комунікабельності у системі «лікар-пацієнт», що необхідно для формування професійно-комунікативної культури.

\section{Jimepamypa:}

1. Rebecca Mitchell \& Stephen Nicholas (2006). Knowledge Creation in Groups: The Value of Cognitive Diversity, Transactive Memory and Open-mindedness Norms. Electronic Journal of Knowledge Management. (University of Sydney, Australia)

2. Климов, Е. А. (1990). Как выбрать профессию. Москва: Просвещение.

3. Литвинчук, Л. \& Чистяк, О. (2019). Розвиток символічного засобу комунікації особистості методами музичного впливу: психофізіологічне дослідження на основі візуального та звукового біологічного зворотного зв'язку. Збірник наукових пращь Наиіональної академії Державної прикордонної служби України. Серія: психологічні науки. Хмельницький, № 1. C.158-165. URL:http://nbuv.gov.ua/UJRN/Vnadpn_2019_1_5

4. Matusitz J. (2014). Effective doctor-patient communication: An updatedc examination. Soc Work Public Health. Vol. 29. P. 252-266. 


\section{References:}

1. Mitchell, R. \& Nicholas, S. (2006). Knowledge Creation in Groups: The Value of Cognitive Diversity, Transactive Memory and Open-mindedness Norms. Electronic Journal of Knowledge Management, 4(1), 67-74 [in English].

2. Klimov, E. A. (1990). Kak vybrat professiyu [How to choose a profession]. Moscow: Prosveshchenie [in Russian].

3. Lytvynchuk, L. \& Chystiak, O. (2019). Rozvytok symvolichnoho zasobu komunikatsii osobystosti metodamy muzychnoho vplyvu: psykhofiziolohichne doslidzhennia na osnovi vizualnoho ta zvukovoho biolohichnoho zvorotnoho zviazku [Development of the symbolic means of communication of the person by methods of musical influence: psychophysiological research on the basis of visual and sound biological feedback]. Zbirnyk naukovykh prats Natsionalnoi akademii Derzhavnoi prykordonnoi sluzhby Ukrainy. Seriia: psykholohichni nauky - Collection of scientific works of the National Academy of the State Border Guard Service of Ukraine. Series: psychological sciences, 1, 158-165. Retrieved from http://nbuv.gov.ua/UJRN/Vnadpn_2019_1_5 [in Ukrainian].

4. Matusitz, J. (2014). Effective doctor-patient communication: An updated examination. Soc Work Public Health, 29, 252-266 [in English]. 